\title{
Propiedad intelectual y asignación eficiente del beneficio social de las innovaciones*
}

\author{
Michele Boldrin y David K. Levine \\ Washington University in Saint Louis
}

\section{Resumen}

En la teoría moderna de la innovación, el monopolio juega un papel crucial tanto como causa, así como efecto de la actividad creativa. Habitualmente se afirma que las firmas innovadoras no tendrían suficiente incentivo para innovar sin el prospecto de un monopolio. En este trabajo argumentamos que el monopolio no es ni consecuencia ni es necesario para la innovación. Demostramos por qué los argumentos que se utilizan habitualmente para defender los derechos de propiedad y los que se utilizaron por el Congreso y la Corte Suprema de los EE.UU. para extenderlo son infundamentados desde el punto de vista del análisis económico y también desde el punto de vista empírico. Mostramos que en la mayoría de las circunstancias las rentas competitivas posibilitarán a los individuos a obtener suficiente parte del beneficio social de las innovaciones como para compensar su costo de oportunidad. Proponemos finalmente, la eliminación de la propiedad intelectual como regla general a favor de un sistema de mercado competitivo.

Clasificación JEL: X15, X16, D42, D62.

Palabras clave: innovación, propiedad intelectual.

\begin{abstract}
In the modern theory of innovation, monopoly plays a crucial role both as a cause and as well as an effect of creative economic activity. An innovative firm wouldn't have enough incentive to innovate without the prospect of monopoly power. In this paper we argue that monopoly is neither a cause for, nor a necessary consequence of innovation. In particular, intellectual property is not necessary for innovation and growth. We show that competitive rents allow creative individuals to appropriate a large enough share of the social surplus generated by their innovations to compensate for their opportunity cost. We provide various examples of how competitive markets for innovative products would work in the absence of IP and critically discuss a number of common fallacies in the previous literature. Therefore, our conclusions are that the IP shouldn't be the default, but rather the exception.
\end{abstract}

JEL classification: X15; X16; D42; D62.

Keywords: innovation, intelectual property.

* Título original: «Intellectual Property and the Efficient Allocation of Social Surplus from Innovations». Traducción a Cargo de Federico Todeschini. Michele Boldrin agradece la financiación recibida del proyecto SEJ-2005-08783-C04-01. 


\title{
1. Introducción
}

\begin{abstract}
«La única patente válida es aquella sobre la cual la Corte Suprema no ha puesto sus manos» [Juez Jackson en Jungerson versus Ostby and Barton Co. 335 US 560, 80 USPQ 32 (1948).]
\end{abstract}

Los tiempos han cambiado desde que el Juez Jackson escribiera su opinión disidente en 1948. El mundo parece dirigirse en la dirección contraria y ha entrado oficialmente en la era de Propiedad Intelectual Universal (UIP). Cualquier persona, haciendo en algún lado alguna «cosa» que considere «útil» y «novedosa», puede y debería reclamar el monopolio total y exclusivo sobre la «cosa», sus usos, sus copias y sus variantes similares. La «cosa» puede ser un objeto manufacturado, un proceso de producción, un método de negocios, un código de ordenador, una semilla de planta, una especie de animal, o simplemente un concepto utilizable, como por ejemplo, «cómo meter un gol».

Siempre habrá una corte de apelaciones para el Circuito Federal de EEUU, dispuesta a clasificar la situación como «una idea nueva susceptible de explotación comercial». La Propiedad Intelectual Universal ha adquirido la categoría de religión, en cuyo centro se encuentra la impactante y profunda relevación: Cualquier cosa que pueda ser monopolizada se debe a quien sea que la reclame primero. A partir de ahí florecerá la prosperidad económica, algo que los profetas de esta nueva religión no se cansan de recordarnos.

En el mundo, la marea está subiendo: India acaba de ajustar su ley de patentes para cumplimentar los requerimientos TRIPS, particularmente en farmacéutica y biotecnología. China, aunque más lentamente, está haciendo lo mismo tanto para copyright como patentes. La Unión Europea avanza con el plan de harmonización Europeo de Patentes. Méjico, Brasil y otros países en vías desarrollo están siendo presionados para adoptar rápidamente la misma senda. El hecho que el Parlamento Europeo, en un insólito momento de sabiduría y perspectiva, haya rechazado la propuesta de patentar el software a fin de compensar al Señor Gates por los inconvenientes que le trajo a Microsoft una moderadamente diligente Comisión de Competencia durante los últimos seis años, es únicamente un contratiempo. La marea está subiendo y nada parece capaz de detenerla; un exitoso panfleto nos recordaba hace sólo unos años que «Los Rembrandts (está escondidos) en el ático» y que la «mayor oportunidad sin explotar» está esperando ser aprovechada por los astutos explotadores de patentes y copyright. Pero, ¿es esto una razón para tratar de frenarla? ¿Qué está mal con la idea y funcionamiento de la Propiedad Intelectual Universal?

Para entender que está mal en la UIP, deberíamos considerar la simple metáfora que parece inspirar a sus actuales defensores. Su amada metáfora dice que el proceso de asegurar la propiedad intelectual sobre las ideas es lógica y económicamente equivalente al establecimiento de unos derechos de propiedad bien definidos sobre una parcela de tierra sin propietario. Sin unos derechos de propiedad bien definidos, las tierras fértiles de la frontera oeste no serían cultivadas o utilizadas para pastura 
en forma eficiente, reduciendo enormemente el desarrollo económico. En forma similar, si la propiedad privada de las ideas no le pertenece a alguien en particular, nunca serían desarrolladas y llevadas a buen puerto. Los territorios abiertos e inexplorados de las ideas rentables y apropiables están ahí, justo delante de los bravos colonizadores del Tercer Milenio (abogados principalmente). Las ideas forman el fértil y productivo campo de la nueva economía que conquistaremos -batalla legal tras batalla legal, lobby tras lobby- y dispondremos finalmente para un uso rentable, liberándolas, en el momento apropiado, de aborígenes, forajidos indeseables, ocupadores ilegales y piratas de todo tipo y raza.

Esta es la nueva película UIP, que se proyecta en teatros de todo el mundo y por lo tanto también cerca tuyo. Este artículo pregunta: ¿Puede haber algo malo en la UIP? Nuestra respuesta es bastante radical, ya que de hecho encontramos que esta visión es incorrecta en casi todo. Nos concentramos en las teorías legales de Propiedad Intelectual (IP) que tienen un sustento económico, esto es: las teorías que argumentan que la UIP es un estado del mundo deseable porque de alguna manera maximiza el bienestar social y lo asigna eficientemente entre sus potenciales pretendientes. Por lo tanto, no nos centraremos en las teorías legales de IP basadas en derechos naturales, teorías axiomáticas de justicia, o cualquier principio metafísico o ético. En particular, no podemos rechazar la hipótesis que los fundamentos de la UIP son básicamente una verdad revelada, y por lo tanto haciéndola irrefutable.

\section{Ideas de Dominio Público}

\subsection{Eldred versus Ashcroft}

Una batalla histórica por el advenimiento de la frontera UIP fue peleada y ganada hace un par de años en el Congreso de los Estados Unidos, y su subsecuente resultado gravado a fuego por la Corte Suprema de los Estados Unidos. En 1998 el Congreso de EE.UU. extendió en 20 años la duración del copyright (a través de la Ley de Extensión del Copyright, más conocida como «Ley Sony Bono»), al tiempo que extendía también su amplitud y endurecía duramente las penas asociadas a su violación (mediante la Ley del Copyright del Milenio Digital). La extensión del copyright fue retroactiva, aplicando no solo a los trabajos nuevos sino también extendiendo los existentes. A pesar del obvio y conocido argumento económico ${ }^{\mathrm{i}}$ sobre que extender el copyright a trabajos existentes no tiene consecuencias sobre su oferta, un número de argumentos falaces ${ }^{2}$ fueron utilizados para demostrar como la extensión retroactiva serviría de algún modo para «promover el progreso de [...]

\footnotetext{
${ }^{1}$ Entre otros, ver http://cyber.law.harvard.edu/openlaw/eldredvashcroft/amici/economists.pdf

2 Por ejemplo, MILLER (1995), reproducido como un Testimonio Legislativo y disponible en http://www.public asu.edu/ dkarjala/legmats/hatch95.html, que incluye también un crítica meticulosa de Dennis S. Karjala al argumento de Miller.
} 
las artes útiles.» ${ }^{3}$ Subsecuentemente, la Corte de Suprema de los EE.UU. adhirió a esos principios en su fallo Eldred et al. Versus Ashcroft, No. 01-618, 15 de Enero del 2003. La Corte por mayoría falló que (Plan de Estudios, pp. 2-3):

La corte no ha hallado nada en el texto constitucional o en la historia que sugiera que la duración de ciertos años de un copyright deja de ser por un «tiempo limitado» si luego es extendida por otro «tiempo limitado»[...]. En la visión de los demandantes, la prescripción, una vez fijada, se vuelve «fija»o «inalterable» para siempre. Sin embargo, la palabra «limitado» no sugiere una significado tan estricto. Al momento de enmarcar la Constitución, «limitado» significaba lo mismo que hoy: confinar dentro de ciertos límites, restringidos o circunscriptos. Esto se entiende, un lapso de tiempo apropiadamente «limitado» aplicado a copyright futuros no dejará automáticamente de estar «limitado» cuando se aplica a copyright existentes. [...] La historia revela una incesante práctica legislativa de otorgarle a los autores de trabajos con copyright existente el beneficio de las extensiones en la duración del copyright, de forma tal que todo lo que tenga protección de copyright sea gobernado de forma equitativa bajo el mismo régimen. Mas aún, debido a que la Cláusula que autoriza al Congreso a conferir derechos de propiedad también autoriza sobre patentes, la investigación de la Corte es propiamente advertida por el hecho que las primeras Legislaturas extendieron la duración de numerosas patentes individuales como así también derechos de autor. Los Tribunales inferiores no han visto en «tiempos limitados» impedimentos a dichas extensiones. Mas allá, a pesar de que esta Corte nunca antes había tenido la ocasión de decidir si los copyright existentes cumplían con la prescripción de «tiempos limitados», la Corte no halla ninguna barrera constitucional a la expansión legislativa de patentes existentes. Ver, por ejemplo, McClurg, como en el 206 Congreso, la práctica histórica refleja un criterio consistente de que un autor que ha vendido su trabajo una semana antes no debería ser encontrarse en una situación peor que la de un autor que vende su trabajo el día después de la promulgación de la extensión del copyright. La CTEA prosigue con esta práctica histórica manteniendo la esencia de las provisiones de la Ley de 1976, simplemente añadiendo 20 años a cada una de ellas.

La CTEA es un ejercicio racional de la autoridad legislativa conferida por la Cláusula de Copyright. En este punto, la Corte se remite sustancialmente al Congreso. Sony, 464 U.S. en 429. La CTEA refleja el criterio que el Congreso mantiene frecuentemente, criterio que la Corte no puede quitar del dominio de la Legislatura. Un factor clave en la sanción de la CTEA fue la directiva de la Unión Europea (UE) de 1993, que instruía a los países miembros a establecer una término de referencia para el copyright de 70 años luego de la muerte del autor y negar esta duración a los trabajos de cualquier país fuera de la UE que no asegurara la misma duración. Al extender los EE.UU.

\footnotetext{
${ }^{3}$ Constitución de los EE.UU.
} 
la duración de referencia del copyright, el Congreso buscó asegurar que los autores americanos recibieran la misma protección en Europa como sus contrapartes Europeos. La CTEA puede incluso proveer mayores incentivos a los autores Americanos o de otra nacionalidad, a crear y diseminar su trabajo en los Estados Unidos.

Hay dos cosas dignas de mencionar:

a) Que la extensión de la duración que la CTEA implementa es un «ejercicio racional» de la autoridad legislativa del Congreso; lo cual es ciertamente el caso.

b) Que la retroactividad se justifica en tres razones: (i) es una forma de proveer igual trato a todos las personas con un copyright, (ii) es una respuesta de equilibrio al movimiento de la UE de extender el copyright en 70 años, y (iii) debido a que puede proveer mayores incentivos a la creación y diseminación del trabajo que acceder a tener derechos de autor; ninguna de las tres tiene sentido.

La duración de los derechos de autor se ha incrementado repetidamente desde su adopción en 1790 cuando se estableció una duración de 14 años, siendo los principales incrementos en 1831, 1909 y 1976; la última extensión, la Ley de Copyright de 1976, añadió 20 años a la duración existente. La provisión retroactiva de la CTEA, por lo tanto, extiende la duración para los mismos ítems que la Ley de 1976 había extendido en forma retroactiva. A pesar de este hecho obvio, la Corte dice

En cuanto a la afirmación de los demandantes que el Congreso puede evadir la limitación de su autoridad con la combinación «un número ilimitado de 'veces limitadas'» la Corte de Apelación ha fallado que tal error legislativo «claramente no es la situación que se nos presenta.»

Olvidémonos de la peculiar interpretación de la realidad de la Corte y qué puede estar o no planeando el Congreso -después de todo deberíamos esperar hasta el 2018 para que una nueva extensión tuviera lugar- y que incluso en ese caso, la aritmética pondrá a disposición de nuestra ingeniosa Justicia el hecho de que 90 no es un número ilimitado. Tratemos en cambio, de ver porque las razones substantivas formuladas en b) no tienen sentido.

Consideremos en primer lugar el argumento del trato equitativo. La Corte escribe (Pág.14)

Desde 1790, la política del Congreso ha sido la de que el autor de un trabajo hecho en el pasado no debería tener una recompensa menor que la del autor de un trabajo hecho en el futuro solamente porque el Congreso pasara un estatuto incrementando hoy la duración. 
Esto, de hecho, es correcto. Sin embargo uno se pregunta si la misma lógica no debería aplicarse cada vez que el Congreso sanciona una Ley que, al afectar, por ejemplo, el código fiscal afecta la rentabilidad económica que los agentes privados reciben. Cualquier impuesto al ingreso, entonces, debería ser retroactivo dado que no tiene sentido poner un impuesto más alto al ingreso pasado «solamente porque el Congreso sancionara un estatuto» reduciendo la tasa impositiva «hoy». Resulta obvio, que lo misma lógica aplica a los incrementos de impuestos, contribuciones a la seguridad social, tarifas, y por qué no, generar un entorno económico mas interesante, y posiblemente volátil; sin hablar de los procedimientos de presupuesto y cuentas nacionales, para deleite de los mercados financiero esto traería prosperidad gracias a la volatilidad.

Lo más interesante del caso, sin embargo, sería el caso en el que el Congreso -en un no característico acto de racionalidad económica- decidiera reducir la duración del copyright y patente en algún momento futuro. De la misma forma que el Congreso y la Corte Suprema argumentaron en 1998 a favor de la retroactividad, suponemos, la reducción de la duración del copyright debería también ser retroactiva de forma tal de garantizar que «la política del Congreso ha sido la de que el autor de un trabajo hecho en el pasado no debería tener una recompensa» mayor «que la del autor de un trabajo hecho en el futuro solamente porque el Congreso pasara un estatuto» reduciendo «hoy la duración» sea prontamente implementada. Quizás no estamos correctamente entrenados en los subterfugios de la lógica legal, y posiblemente haya algún párrafo oculto en algún lugar de la reglamentación de la Corte explicando por qué razón los poseedores de derechos de autor son agentes económicos de excepcionalidad y, en particular, explicando por qué el tratamiento uniforme únicamente aplica cuando se incrementa la duración y no cuando se reduce. No hemos podido hallar tal párrafo, y por lo tanto la justificación de extensión retroactiva se interpreta como un absurdo creativo económico.

La siguiente motivación, (2 ii) es la de reaccionar a la decisión de la UE de extender la vida del copyright a 70 años después de la muerte del autor. Nuevamente, citando la opinión de la mayoría (Pág.15)

Al extender la referencia de la duración del copyright en los EE.UU. a 70 años luego de la muerte del autor, el Congreso busco asegurarse que los autores Americanos recibieran la misma protección de copyright en Europa que sus contrapartes Europeos. [...] («[I]gualando el nivel de protección de copyright en los Estados Unidos (al de Europa) asegura una protección más fuerte para el trabajo de EE.UU. fuera del país y evita desventajas competitivas vis-à-vis los autores extranjeros.»)

En el caso que se esté preguntando de dónde la Suprema Corte de los EE.UU. obtiene el saber económico, la nota al pie número 12 del reporte de opinión dice «El 
autor del artículo de revisión legislativa citado en el texto, Shira Perlmutter, actual vicepresidente de AOL Time Warner, al tiempo de la sanción de la ley CTEA era el Registrador Asociado para Política y Relaciones Internacionales de la Oficina de Copyright de los Estados Unidos.» Dejemos para más tarde la economía política de la UIP y concentrémonos por el momento en el argumento. ¿Cuál es la lógica del caso? De las propias palabras de la Corte se desprende que es un preocupación meramente redistributiva: si los EE.UU. no aumentan la duración del copyright, los autores Estadounidenses que publican en Europa recibirán en aquel mercado menos dinero que sus contrapartes Europeos.

De nuevo, esto no supone un problema, puesto que la Constitución de los EE.UU. no impide al Congreso redistribuir el ingreso de un grupo a otro mediante legislación. En este caso, el Congreso debe haber temido que los escritores, músicos y actores estrellas que son ciudadanos norteamericanos se volviesen pobres y desnutridos de no existir los 20 años adicionales de ingresos de copyright de los mercados Europeos. En tal caso, no hay ningún punto en discutir: redistribuir de la pobre e indigente estrella de cine al rico y poderoso consumidor sería ciertamente una tarea encomendable al Congreso, si no estuviese explícitamente mencionada por los Padres Fundadores en la Carta de Derechos. Siendo la preocupación sobre la redistribución, uno se pregunta ¿por qué el Congreso no eligió una suma fija y por que la Corte no recomendó lo mismo? Hubiese alcanzado el mismo objetivo igualitario ahorrándonos los efectos de la distorsión que generan 20 años adicionales de monopolio en los mercados para bienes con derechos de autor. Cierto, el votante mediano probablemente hubiera hallado al nuevo impuesto destinado a financiar el consumo de cocaína de las estrellas de Hollywood muy poco patriótico ${ }^{4}$.

El principal punto económico es que la decisión de la UE de extender la duración del copyright para sus ciudadanos es totalmente irrelevante para el bienestar de los ciudadanos Norteamericanos o sus autores; en el mejor de los casos, mejora su bienestar siempre y cuando la duración del copyright no se haya extendido también en los Estados Unidos. Veamos por qué. Consideremos primero la razón económica fundamental para otorgar el copyright - los detalles serán exhaustivamente analizados más adelante. Esta dice que el copyright se otorga a los creadores para garantizar un ingreso suficiente como para compensar su esfuerzo creativo. Los consumidores, por lo tanto, se benefician indirectamente del copyright, puesto que si bien pagan un precio de monopolio reciben la creación a cambio y, de no existir el copyright, no recibirían nada. La decisión de la UE incrementa dicha renta para los creadores Europeos, y deja inalterado al resto, siempre y cuando la duración del copy-

\footnotetext{
${ }^{4}$ En caso que le parezca algo irrespetuoso nuestro tono hacia la Corte Suprema, lo lamentamos. No obstante, la parte que citamos es literalmente el único argumento que dio la Corte para dar sustancia a la idea de que es una buena política nacional que el Congreso de los Estados Unidos legisle de acuerdo a los deseos de la Comisión de la Unión Europea en Bruselas. Ciertamente, podríamos utilizar un enfoque alternativo y argumentar, basado en la Ley Patriótica post 11 de septiembre, que la legislación de los EE.UU. debería expresar la voluntad de los ciudadanos de los EE.UU. y no la de los tecnócratas de Bruselas, que además probablemente sean anti americanos.
} 
right no fuera reducido dentro de sus países o para los de la UE. Esto implica que: a) los creadores de la UE son más ricos, b) los consumidores de la UE pueden o no estar mejor (supuestamente recibirían mas creaciones, pero lo que es seguro es que tienen más distorsiones de precio), c) los creadores de los EE.UU. no se encuentran peor dado que reciben al menos la misma renta que recibían antes ${ }^{5}$, d) los consumidores Norteamericanos se encuentra mejor dado que continúan pagando el mismo precio por el trabajo creativo, pero disfrutan de un mayor número (supuestamente) de creaciones Europeas.

En pocas palabras, al extender la duración del copyright en 20 años, la UE forzó a sus consumidores a una proposición arriesgada -más distorsiones con probabilidad 1 y más cultura con probabilidad menor a uno- para hacer a sus creadores más ricos. También le hizo un favor similar a los creadores y consumidores Norteamericanos al mejorar su posición en el mercado. Con respecto a la CTEA, el Congreso de los Estados Unidos se aseguró que los consumidores fueran forzados a la misma proposición arriesgada, empeorándolos con respecto a su situación en el período intermedio; este es el precio pagado para transferir mayores rentas a los creadores Norteamericanos.

Por lo tanto, llegamos a la misma conclusión que antes, esto es, la CTEA se explica por el deseo de transferir ingreso desde los consumidores a los productores de bienes con potencial copyright Norteamericanos, y no mejora la eficiencia económica ni es una respuesta apropiada frente a la decisión de la UE. En particular, las «desventajas competitivas» que el vicepresidente de AOL menciona siguen siendo un misterio. ¿Cuáles podrían ser? Si los EE.UU. no hubieran extendido la duración, las editoriales, discográficas y estudios de película podrían haber puesto en EE.UU. muchas creaciones Europeas con un copyright expirado (en los EE.UU.), mientras que sus contrapartes Europeas deberían haber esperado otros 20 años. Esto nos parece una ventaja, y no una desventaja. Al mismo tiempo, en los mercados europeos, las subsidiarias europeas de las editoriales podrían haber aprovechado la mayor duración del copyright para ganar más beneficios monopólicos a expensas de los consumidores europeos. En el peor de los casos, si la UE no hubiera permitido que las subsidiarias europeas de las empresas Americanas utilizaran los 20 años adicionales de protección de copyright, habrán estado en la misma instancia competitiva que tenían hasta 1998.

Finalmente, tenemos el tercer punto, que es el más consistente desde el punto de vista económico (pág. 16)

\footnotetext{
${ }^{5} \mathrm{El}$ uso de la frase «al menos» $\mathrm{y}$ «no peor» es intencional. De hecho, siempre que la demanda por trabajo creativo tenga pendiente negativa y el trabajo creativo sea sustituto parcial entre sí, los creadores de los EE.UU. serían mas ricos. Esto se debe a que el precio de monopolio es mayor al precio de competencia, y por lo tanto, si el precio de los creadores europeos aumentase una vez que incrementada la duración del monopolio en Europa, los creadores norteamericanos pueden mantener sus productos tan competitivos en los mercados Europeos como lo eran antes, incluso subir marginalmente sus precios.
} 
Adicionalmente a las preocupaciones internacionales, el Congreso sancionó la CTEA en luz de los cambios demográficos, económicos y tecnológicos, Minuta de Respuestas 25-26, 33 y nn.23 y 24, y las proyecciones racionalmente acreditadas que aseguran que un mayor término de duración incentivaría a los dueños de copyright invertir en la restauración y distribución publica de sus trabajos, id., en 3437; ver H. R. Rep. No. 105-452, p. 4 (1998) (la extensión de la duración «otorga a los dueños de copyright el incentivo a restaurar sus antiguos trabajos y diseminarlos entre el publico»).

A cuáles «predicciones racionalmente acreditadas» la Corte hace referencia, no lo sabemos, aunque tampoco nos importa; siempre habrá alguien en algún lugar con cierto Ph.D. en Economía de alguna institución dispuesto a predecir que los elefantes volarán si el código tributario no es corregido en la forma que recomienda el lobby que financia su investigación. Como la Corte no reporta ningún número, y en ningún lado de la literatura se pueden hallar números creíbles que sostengan tal pronóstico, trabajaremos sobre los fundamentos teóricos. Siendo sinceros, estos no están muy claros en la opinión de la Corte. En particular, las notas al pie que uno puede hallar entre la página 16 y la 19 -que supuestamente fundamentan los incentivos- son mas bien decepcionantes. Aparentemente, la Suprema Corte de los EE.UU. cree que desde 1976 la esperanza de vida de los inventores se ha incrementado en 20 años, lo cual es más o menos 10 veces el valor real. De la misma forma, la misma Corte cree que Quincy Jones, Bob Dylan, Carlos Santana y Don Henley compusieron lo que compusieron y tocaron lo que tocaron debido a (Pág. 17, nota al pie 15)

la convicción que la compensación justa que el sistema de copyright aseguraba para ellos y para sus herederos, era un incentivo para crear.

No hay ningún otro argumento dado para fundamentar la teoría de incentivos, y por lo tanto, sin querer faltarle el respeto de la Suprema Corte de los Estados Unidos, debatamos con los académicos que, en una forma más o menos articulada, han argumentado a favor de que tales incentivos existen, son sustanciales y salen de una bien fundamentada teoría microeconómica. Como Willian M. Landes y Richard A. Posner parecen ser los más prolíficos y coherentes partidarios de este pensamiento dentro de la literatura de Economía y Derecho, es a sus más recientes escritos a los que nos referiremos (Landes y Posner, 1989 y 2003, y Posner, 2003).

\subsection{Ejercicio académico}

Los dos argumentos más importantes son que cualquier tipo de invención no debería ser de dominio público debido a que el dominio público sufre de congestión y sobre utilización, y el segundo es que los derechos de propiedad intelectual son 
necesarios para proveer los incentivos correctos no solo para «crear» sino también para «mantener» trabajos existentes. Es digno de notar la similitud con el argumento «la propiedad privada del suelo es positiva» y también notar que el argumento dice que la propiedad privada no solamente incentiva la creación de nuevas cosas sino también incentiva el mantenimiento.

Por lo tanto, para el caso del copyright, esta línea de razonamiento, en el límite, avala la duración ilimitada del copyright. También es interesante notar que esta línea de argumentación depende del principio que en las bases normativas del derecho esta la maximización de la riqueza social, por ejemplo alcanzar la eficiencia económica en el sentido de Pareto -independientemente de sus consecuencias distributivas entre agentes heterogéneos. Aquí no cuestionamos ese principio- a pesar de los cuestionamientos personales y filosóficos tanto con la fundamentación lógica como con las implicancias morales - y en lo que sigue utilizaremos dicho criterio.

Comencemos por la metáfora que iguala las ideas a la pastura:

La contraparte de la pastura compartida en la propiedad intelectual es el dominio público[...] El término se refiere al conjunto vasto de ideas y expresiones que no tienen copyright, patentes o propiedad. [Landes y Posner, 2003, Pág. 13]

Una de las razones para la existencia de derechos en las propiedades ordinarias es, de hecho, prevenir la congestión y la sobre utilización. Por ejemplo, si la pastura es pública, no tengo en cuenta el efecto negativo que el pastoreo de mis ovejas tiene sobre la disponibilidad de pasto para tus ovejas. Debido a que los caminos son públicos, no tomo en consideración el hecho de a ti te es más difícil llegar a tu trabajo a consecuencia de que yo utilice el camino. Debido a que el océano es público, no considero que mi pesca deja menos peces para ti. Esto se denomina «la tragedia de los comunes» y dice que en cada caso, ya sea el pasto, los caminos o el océano, los bienes de dominio público se sobre utilizarán.

Contrario a la creencia popular, más frecuente en los círculos legales, el dominio público de las ideas es la antitesis lógica y practica al pasto/camino/océano. El dominio público de ideas es una condición necesaria (no suficiente pero si estrictamente necesaria) para la competencia en esos mercados, y por lo tanto para la eficiencia social. En este no concentraremos, y ese será el contenido de esta sección.

¿Se puede comparar el dominio público de ideas a los comunes? ¿Utilizar ideas de dominio público genera algún efecto adverso en tu capacidad para utilizarlas? Ciertamente el sentido común sugiere que «no puede haber sobre pastoreo de propiedad intelectual...puesto que la propiedad intelectual no se destruye ni disminuye con el consumo.» ${ }^{6} \mathrm{El}$ hecho que yo utilice una idea no hace que tengas menos posibilidades de utilizarla. De hecho, parece obvio que el bienestar general incrementa cuando más personas se familiarizan con una idea útil, mientras que la capacidad

\footnotetext{
${ }^{6}$ KARJALA [1998], citado en LANDES y POSNER [2003].
} 
productiva no se incrementa cuando más ovejas tratan de comer del mismo metro cuadrado de pasto, o cuando distintos equipos de salvamento compiten por un barco hundido.

Como hemos visto, el Congreso y la Corte Suprema no están de acuerdo, y Landes y Posner ${ }^{7}$ afirman además que «se ha tardado en reconocer el problema del sobre pastoreo en los trabajos con potencial derechos de autor.» Esto de hecho no ha ocurrido, puesto que no existe ninguna teoría bien fundamentada o evidencia alguna que señale la existencia de tal problema.

Hay tres elementos claves para entender por qué los argumentos a favor de los derechos de autor retroactivos son incoherentes. El primero es que sólo las copias de las ideas importan desde un punto de vista económico; de hecho, ¡desde cualquier punto de vista, únicamente las copias de las ideas importan! Si todas las copias desaparecieran -tanto de los libros como de las mentes-, la existencia abstracta de la idea no tendría uso alguno, al menos para el hombre práctico, mientras que sí podría ser de uso alguno para el hombre metafísico que parece habitar las revistas legales.

Segundo, el dominio publico no es un común de ideas sin dueño o de propiedad pública. Cuando una idea es de dominio publico, hay alguien que todavía es dueño de cada copia de esa idea o trabajo. Para realizar copias deberías primero comprar una copia de la idea o ser dueño de esta. Más que un común, el dominio público es como un mercado competitivo ideal -como el del trigo- con muchos dueños/productores de un producto esencialmente similar compitiendo entre ellos. Por último, y a pesar de que mi uso de una idea no impide que la utilices, si puede hacer que tengas menos posibilidades de venderla. Esto es, el hecho de que sea dueño de una copia de la misma idea que tu no hace que la idea sea menos valiosa desde un punto de vista social, pero ciertamente reduce el valor de mercado de tu copia de la idea. Los economistas denominan como una «externalidad pecuniaria» al hecho de que mi venta cambie la demanda por tu producto y lo consideran un aspecto muy positivo de las economías competitivas. Los consumidores están mejor ya que como el precio lo determina el consumidor marginal, esto es, aquel que menos valora el bien, permite que todo aquel que lo valora más pueda adquirirlo con un beneficio sustancial, al comprarlo por un valor menor a su utilidad marginal, lo que hará que existan muchas copias del mismo bien.

Consideremos el caso de la comida. Si mi restaurante le vende a Ricardo una cena completa, es improbable que el cruce la calle y vaya a tu restaurante y cene otra vez; mi venta no impide que él compre tu comida, pero si impide que le puedas vender a Ricardo. Y lo mismo pasa con las ideas. Si le vendo una copia de mi Biblia a Ricardo, no te estoy impidiendo hacer copias de tu Biblia, pero si disminuyo tu beneficio debido a que Ricardo ya no te la comprará a ti. Esta es una externalidad pecuniaria. Como contraejemplo, al quitar peces del mar no solamente te estoy quitando mercado sino que también estoy quitando un insumo útil. Los economistas se

\footnotetext{
${ }^{7}$ La discusión Landes y Posner de sobrepastoreo y mantenimiento puede encontrarse en págs. 222-
} 234 de [2003]. 
refieren a esta última como «externalidad tecnológica». Las externalidades pecuniarias son positivas -el incentivo a ganar consumidores es una parte esencial de un sistema competitivo normal y eficiente. Las externalidades tecnológicas no son deseables, dado que conllevan sobre utilización.

Los defensores de la propiedad intelectual, y de la extensión del copyright en particular, parecen no distinguir la diferencia. Landes y Posner, quienes proveen el argumento menos incoherente de todos de por qué la extensión retroactiva del copyright puede ser positiva, reconocen que la «evaluación de los efectos de la congestión sobre el bienestar requiere distinguir entre externalidades tecnológicas de las pecuniarias». Los autores luego prosiguen relacionándolo con el Ratón Mickey. «Si a causa de que el copyright ha expirado cualquiera fuese libre para incorporar al ratón Mickey en un libro, película, canción, etc., el valor del personaje caería en picada.» ¿El valor para quién? No puede ser que el valor social del Ratón Mickey sea lo que desaparezca -este se incrementa cuando más gente puede utilizarlo.

En realidad es el precio de las copias del personaje del Ratón Mickey lo que se evaporaría. Como Landes y Posner lo admiten, «Si esto ocurriera...como consecuencia de un aumento del producto, entonces el valor agregado podría aumentar» Luego los autores aseguran «sin embargo, el público se cansaría rápidamente del Ratón Mickey». Pero esto de hecho es la consecuencia de un incremento en el consumo del producto. Si tengo un almuerzo completo, tengo menos hambre - el valor para mí de un almuerzo ha disminuido, y los restaurantes verán que no estoy dispuesto a pagarles mucho dinero por almorzar. No hay ninguna externalidad involucrada: mientras más de un bien es consumido, más hastiada del bien se sentirá la gente. Para que halla una externalidad involucrada tendría que ocurrir que mi consumo del Ratón Mickey hace que tu te canses más del personaje - algo improbable cuando menos.

Aunque Landes y Posner distinguen verbalmente entre externalidad pecuniaria y tecnológica, no demuestran comprenderla. Citan un libro de marketing de Disney: «Para evitar perder el negocio, Disney maneja su porfolio con cuidado. Tiene cientos de personajes en sus libros, muchos de ellos esperados ser llamados a retiro...Disney lleva una apropiada crianza de sus personajes y extiende la vida de sus marcas no sobreexponiéndolos... Evitan degradar la moneda.» ${ }^{8}$ Esto es exactamente lo que esperaríamos de un monopolista. Si Disney tuviera el monopolio de la comida, podríamos estar seguros de que practicaría una «buena crianza» de la comida, probablemente dejándonos al borde de la hambruna. Esto sería bueno para Disney, dado que todos estaríamos dispuestos a pagar un precio mayor por obtener comida. Pero las perdidas para el resto superarían las ganancias de Disney. Es una alivio saber que el Ratón Mickey no es una parte esencial de la dieta Americana.

Hay un serio problema en la interpretación de eficiencia económica que, aparentemente, se ha hecho común entre los académicos legales. En el ejemplo anterior,

${ }^{8}$ BRITT [1990], págs. 22 y 26. 
quitarle a Disney el poder de monopolio sobre la comida es frecuentemente interpretado como algo no necesariamente eficiente. Esto se debe a que si bien luego de que se introdujera la competencia en el mercado de comida los consumidores estarán mejor, existe una entidad llamada Disney que se encuentra peor. Este no es precisamente el mejor lugar para discutir los teoremas de bienestar, pero es el lugar apropiado para mencionarle al lector interesado lo equivocado del argumento.

Landes y Posner también expresan su preocupación de que «la imagen del Ratón Mickey también se desvanezca o incluso cambie, cuando algunos autores lo retraten como un Casanova, otros como alimento de gatos, otros como un abogado de los derechos animales, y otros como el esposo de Minnie.» Puesto que en la jerga común denominar algo como Ratón Mickey no es exactamente un cumplido, uno se podría preguntar por qué la reputación del Ratón Mickey podría verse afectada. A pesar de ello, recordemos que lo único que importan son las copias de la idea del Ratón Mickey. Si el Ratón Mickey pasa a ser de dominio público, alguien podría usar su copia para producir, por ejemplo, una película pornográfica con el Ratón Mickey como actor. ¿Pero podría esto afectar las copias de la idea de Mickey en las mentes de millones de niños de 6 años? Es difícil ver como podría ocurrir: los chicos de esta edad normalmente no tienen permitido ver películas pornográficas. Probablemente aquella gente que elije mirar la película son aquellos que se benefician de este retrato del Ratón Mickey. ¿Cómo puede este proceder interferir de forma alguna con la forma en que el resto disfruta de la imagen del Ratón Mickey? Para poner las cosas en perspectiva, uno de nosotros considera un signo de mal gusto ponerle queso Parmigiano sobre cualquier tipo de pasta con salsa que contiene comida de mar. Sin embargo esto no evita estar casado y disfrutar cenar con su esposa, quien tiene preferencias opuestas: siempre que haya pasta, el queso Parmigiano es bienvenido, sin importar la salsa. En las infrecuentes ocasiones en las que hay disponible sólo un plato de pasta con salsa de almejas, se crea un pequeño debate que reduce el bienestar general. Lo que debería dejar perfectamente claro porque es socialmente bueno que halla tantas copias del Ratón Mickey como sea posible, así como también platos de pasta similares.

Para comprender más claramente la distinción entre externalidades pecuniarias y tecnológicas, consideremos el caso de la música. Por lejos, el hecho que yo escuche una copia de mi música no interfiere con tu habilidad para escuchar tu copia de tu música - no hay externalidad alguna. En cambio, si pongo la música muy alta, puede interferir con tu capacidad para disfrutar de la música. Una solución a esta externalidad tecnológica seria otorgar un monopolio en la venta de equipos de música a la Disney Corporation. Como buen monopolista, limitará la oferta e incrementará el precio de los equipos de música. Como resultado, no podré comprar un equipo tan potente y deberé escuchar mi música a un volumen más bajo, reduciendo la externalidad. Las externalidades negativas leves son comunes en el día a día. Una «solución» es la creación de monopolios que limiten la oferta de los ingredientes que producen externalidades. Pero la mayoría de nosotros entiende que la «cura» es peor que la enfermedad. A pesar de que los autos son grandes generadores de externali- 
dades negativas, desde contaminación del aire a acústica, a nadie se le ha ocurrido solucionar el problema creando un monopolio mundial de autos.

Landes y Posner continúan diciendo que «Un propósito de otorgarle al dueño de un copyright un monopolio sobre trabajos derivados es facilitar el alcance y momento de la explotación del trabajo patentado - para evitar, por ejemplo, la 'congestión' que resultaría una vez que el trabajo se publicara y todo el mundo pudiera hacer y vender traducciones, adaptaciones, burlas, secuelas, versiones en medios distintos del original (por ejemplo, la adaptación de un libro a película), otras variantes...El resultado sería una prematura saturación del mercado, confusión en el consumidor (por ejemplo, en la fuente del trabajo) y una reducción en la demanda por el trabajo original debido a la poca calidad de algunos de los trabajos derivados no autorizados.» Este argumento nos parece que está en contra de la realidad y es profundamente anti mercado y anti competencia. Sí, el mercado competitivo esta lleno de productos 'interesantes'. Podemos comprar camisas, chaquetas y zapatos de muchas marcas, estilos y colores.

Sin embargo los consumidores aparentemente no son lo profundamente ignorantes como para no distinguir qué marcas, estilos, colores y productos desearían comprar; aparentemente no necesitan que la Disney Corporation decida por ellos. En los mercados competitivos del mundo libre hay cantidades de buenos productos, productos excelentes e incluso más de baratos y de menor calidad. ¿Y qué? Seabright [2004] alaba la diversidad de productos que produce la competencia; Lindsey [2001] nos advierte sobre los que no confían en la descentralización del libre mercado y desean la «mano muerta» de la autoridad central para que ordene la confusión. A diferencia de Landes y Posner, no vemos la necesidad de la autoridad organizativa del monopolista para sustituir la diversidad del mercado.

En un esfuerzo por otorgarle contenido a su argumento, Landes y Posner señalan tres ejemplos de «trabajos de...elite cultural que fueron dañados por la reproducción ilimitada:» la Mona Lisa, la obertura de la Quinta Sinfonía de Beethoven y varios de los cuadros mas populares de Van Gogh's. Nos gustaría saber qué evidencia tienen Posner y Landes para hacer tal aseveración. Si buscamos la palabra «Beethoven» en la categoría música clásica dentro de Amazon da tres ítems como los más populares. El primero es una colección de las 9 sinfonías; el segundo es una compilación de la 5. ${ }^{\mathrm{a}}$ y $7 \mathrm{a}^{\mathrm{a}}$. Así que aparentemente, a pesar del daño causado por la reproducción ilimitada, la $5 .^{\text {a }}$ todavía es muy venerada por mucha gente $-i$ o debemos suponer que saltean la obertura porque fue dañada por la reproducción ilimitada? ¿O acaso los Profesores Landes y Posner sufren la tendencia esnobista europea de considerar que las obras de arte se degradan cuando se vuelven conocidas y apreciadas por las masas «no refinadas»?

El argumento de mantenimiento es prácticamente opuesto al de «sobre pastoreo». Aquí se supones que sólo un monopolio tiene los incentivos adecuados para realizar un «mantenimiento» de las ideas. El ejemplo extremo del argumento de «mantenimiento» es que el monopolio del copyright incrementará la disponibilidad, al punto de decir que «la falta de derechos de autor imposibilitara la diseminación 
del trabajo.» ${ }^{9}$ Lemley [2004], quien critica lo que él se refiere como argumentos ex post, lo pone sucintamente, sobre bases parecidas a las nuestras ${ }^{10}$ : «Es difícil imaginar a los Senadores, lobitas y académicos argumentar que el gobierno debería otorgarle a una empresa el derecho perpetuo para controlar la venta de todos los clips de nuestro país, basado en la teoría de que de otra forma nadie tendría el incentivo a distribuir clips.» Lemley también cita evidencia empírica que muestra que los trabajos de dominio público están mucho más disponibles que los trabajos del mismo período de tiempo que aún tiene un copyright vigente. ${ }^{11}$

Un argumento un poco menos ridículo es el siguiente: podemos suponer que Disney tendría menos incentivos para producir nuevas películas del Ratón Mickey si enfrentase competición en el mercado para muñecos del Ratón Mickey -algunos de los buenos sentimientos por el Ratón Mickey despertados gracias la película se volcarían hacia un aumento de la demanda por muñecos del Ratón Mickey producidos por otros. Esto parecería ser, de hecho, una verdadera externalidad, aunque positiva en lugar de negativa; debido a que no hay una forma de compensar a Disney por el efecto positivo que está teniendo sobre la demanda de muñecos, el ingreso que tendrá Disney por la película será demasiado bajo. El problema con este tipo de análisis es que es incorrecto. Las películas y muñecos del Ratón Mickey son ejemplos de bienes complementarios -incrementar la cantidad de uno aumenta la demanda del otro. Pero muchos bienes son complementos: por ejemplo, la manteca de maní y la jalea. Y nadie se preocupa que no habrá suficiente manteca de maní debido a que parte del efecto de producir mas manteca de maní es que incrementa la demanda por jalea. Lo que este argumento está dejando de lado es la reciprocidad: cuando la competencia produzca más muñecos de Mickey, también aumentara la demanda por la película.

Esta falacia se puede ver otra vez en el ejemplo de Landes y Posner de «la Disney Corporation gasta decenas de millones de dólares renovando el personaje del Ratón Mickey, tanto mediante alteraciones sutiles del personaje como situándolo en selectos lugares de entretenimiento, en un esfuerzo por incrementar la imagen de Mickey a la actual generación de niños.» Este es un ejemplo clásico de bienes complementarios -la salida del Mickey «mejorado» aumenta la demanda del Mickey «no mejorado»- pero no hay incentivo adverso ya que el incremento en la oferta del Mickey «no mejorado» a su vez aumenta la demanda por la versión mejorada ${ }^{12}$.

${ }^{9}$ Citado en LEMLEY [2004].

${ }^{10}$ Debemos mencionar que el argumento de Lemley de no hay ninguna razón para que de existir derechos de monopolio se le otorguen al autor, es incorrecto. Más allá de quién comience con los derechos de monopolio, en tanto y en cuanto puedan ser vendidos sin costos de transacción prohibitivos, terminarán en manos de aquel que pueda manejarlos en forma mas eficiente. En la práctica la mayoría de los copyright son transferidos a corporaciones y publicistas. Si los derechos de monopolio deben ser provistos, la ventaja de proveerlos al creador (más allá de la dificultad obvia de averiguar a quien otorgárselos) es que crea un incentivo adicional para crear, por minúsculo que sea.

${ }^{11}$ Ver también KARJALA [2004] y nuestro propio análisis en BOLDRIN y LEVINE [2005b, capítulo 4].

12 Ver que el clásico argumento del costo fijo para la propiedad intelectual se encuentra ausente aquí -Ciertamente Disney puede gastar un millón mas o un millón menos «renovando la imagen de Mickey». 
Landes y Posner también intentan una táctica más sutil. No se concentran tanto en las conexiones entre bienes relacionados, sino más bien en los esfuerzos «promocionales». «Suponga que un estudio piensa sacar una versión en color de una película antigua cuyo copyright ya ha expirado... Promocionar la versión en color incrementaría la demanda por la versión en blanco y negro, un sustituto cercano...el estudio debería tomar en cuenta, al decidir si colorear o no, el incremento en la demanda por la versión en blanco y negro.» Hasta aquí pareciera ser que la promoción de la versión en color, es un complemento tanto del consumo del film a color como de la versión en blanco y negro; dado que se trata de una discusión sobre si los bienes son complementarios, hemos visto que no hay nada que discutir. Pero hay un punto mayor: en todos los mercados competitivos los productores no tienen incentivos en promocionar la industria. Los productores individuales de trigo no tienen mucho incentivo en promocionar las virtudes saludables del trigo, los pescadores no tienen motivo para promocionar lo saludable del pescado y así sucesivamen$\mathrm{te}^{13}$. Es difícil ver como el problema con las películas viejas, libros y música es diferente cuantitativa y cualitativamente que en estos otros mercados competitivos. Sin embargo y con razón, nadie argumenta que se necesita conceder monopolios al trigo o a la pesca para solucionar el «problema» de la sub promoción.

Vale la pena reflejar brevemente las actividades promocionales en las industrias competitivas. La información sobre, digamos, los beneficios sanitarios del pescado, es útil probablemente para los consumidores; de la misma forma es improbable que el pescador individual tenga mucho incentivo para proveer dicha información. ¿Es esto un tipo de falla de mercado? No -en un mercado con propiedad privada, los consumidores deben pagar por la información útil en lugar de obtenerla en forma gratuita. Y de hecho pagan por ello -los doctores, promotores de salud, publicistas proveen este tipo de información a cambio de un pago. No hay evidencia que los mercados competitivos sub provean esta información. Por el contrario, en el caso del monopolista, debido a que el valor del producto va principalmente al monopolista y no al consumidor, el consumidor tiene poco incentivo a adquirir esta información, mientras que el monopolista tiene muchos incentivos en asegurarse que el consumidor acceda a ella. Por ello esperamos distintas arreglos en la provisión de información (promoción) entre mercados competitivos y no competitivos. En el primero, los consumidores pagan y los productores competitivos generan la información. En el último, las empresas subsidian la provisión de información ${ }^{14}$.

Irónicamente, Lamdes y Posner dan un apoyo débil a sus propios argumentos. Al referirse a los efectos dañinos del sobre pastoreo, apuntan que «existen contraejemplos: los trabajos de Shakespeare aparentemente no sufren de la descontrolada pro-

${ }^{13}$ De ahí la razón de que las campañas promocionales de la leche, cereales y pescado normalmente son llevadas a cabo por alguna asociación de la industria y no por empresas individuales.

${ }^{14}$ Obvio que a diferencia de los productores competitivos, el monopolista no tiene incentivo a proveer información correcta. Rara vez oímos decir a Disney que, por más cierto que parezca, la nueva película de Mickey es pésima y deberíamos ver la antigua. 
liferación de obras de teatros y trabajos derivados, algunos de ellos 'kitsch' como las camisetas de Shakespeare y la película 'Shakespeare enamorado'.» Podríamos mencionar que comparar alguien con Winston Churchill, a diferencia del Ratón Mickey, es un cumplido y no un insulto. Los autores llegan a la rimbombante conclusión que «existe una preocupación legítima, una que el análisis económico no debería ignorar.» Bueno, dado que no los hemos ignorado del todo, hemos tomado su consejo. Lo que es más impactante de esta tibia conclusión es que Landes y Posner comienzan su libro con una lista de argumentos en contra del copyright y llegan a una conclusión incluso más fuerte: ${ }^{15}$ «Los nueve puntos anteriores constituyen el caso contra la necesidad de un copyright fundamentada por incentivos...y particularmente en contra de la necesidad fundamentada por incentivos de una larga duración del copyright. Ya que incluso con los vulnerables trabajos expresivos...la protección por copyright de [no] más que un par de años [debería ser suficiente] para recuperar razonablemente el costo de crear el trabajo.» Esto es irónico, puesto que hemos visto que los fundamentos no basados en incentivos que ellos tímidamente apoyan son incorrectos.

\subsection{Perdedores}

La opinión de la Corte Suprema en 01-618 contiene únicamente dos opiniones disidentes, una por el Juez Stevens y la otra por el Juez Breyer. En tanto que nosotros estamos de acuerdo con casi todo lo que dicen, sino con todo, no las citaremos, pero en cambio citaremos Breyer [1970]. Esto se debe en parte a que las opiniones disidentes -en particular la del Juez Stevens- se centra más en la retroactividad del termino de duración, y en parte porque las palabras sabias son buenas repetirlas, incluso cuando, y especialmente cuando, pasan desapercibidas.

Contrario a otros académicos legales, Breyer entiende de economía, puesto que puede distinguir que un excedente del consumidor positivo no es un mal resultado, al menos desde un punto de vista social (págs. 285-286)

A menudo se dice que el autor debe recibir el «valor» que tiene su obra para la sociedad-un valor que podría medirse en términos de lo que estarían dispuestos a pagar aquellos que se benefician del libro si no lo tuvieran. Pero muy pocos trabajadores reciben un salario que se aproxima al valor total de lo que producen. [...] los trabajadores en industrias competitivas producen bienes que se venden a precios menores a lo que muchos de sus compradores estarían dispuestos a pagar por ellos. No tenemos la sensación de que los dueños, administradores o los trabajadores de esas industrias por dicha razón tengan derecho moral a salarios más elevados. De hecho, cuando un trabajador que no enfrenta-quizás porque es el único doctor en

${ }^{15}$ LANDES y POSNER [2003] Pág. 50. 
un área, o porque es el único ingeniero capaz de construir cierto puente- puede cobrar un salario que se aproxima al valor que tiene para el comprador de sus servicios, intentamos normalmente generar competencia, lo que lo obliga a cobrar menos.

Sus recomendaciones de política en 1970 eran muy actuales (págs. 350-351)

1. El período de protección de copyright actual es demasiado largo y no debería extenderse mas allá de los 56 años.

2. La legislación debería permitir a los individuos realizar copias individuales de artículos de revista y extractos de libros sin la necesidad de obtener la autorización del dueño del copyright. Los detalles de la excepción pueden determinarse mediante el estudio de la comisión que la revisión de la ley establezca.

3. La legislación debería permitir a los individuos y a los grupos pequeños a guardar material con copyright y utilizarlo para motivos de investigación sin la necesidad de la autorización de los dueños del copyright.

4. En la actualidad, los programas de computación no deberían recibir copyright.

Y la conclusión final

La naturaleza generalmente insatisfactoria de las audiencias del Congreso durante la Revisión de la Ley de Copyright subraya la importancia de esas conclusiones. Las audiencias revelan muy poco análisis crítico de los reclamos industriales sobre la necesidad de más protección. Muestran muy poca percepción de los daños posibles de extender la protección. Por el contrario, los datos acumulados durante la audiencia están desordenados, son hechos y opiniones muchas veces irrelevantes, y faltan hechos críticos de industrias afectadas. Ahora, por supuesto es demasiado tarde: los revisores han tenido un trabajo difícil. Sin embargo uno no puede dejar escapar la conclusión de que se necesita más trabajo empírico y más análisis teórico antes de hacer una revisión significativa la Ley de Copyright.

\section{Más falacias de los comunes}

Ciertamente más trabajo teórico y empírico es necesario para comprender el impacto que la propiedad intelectual tiene sobre la innovación, creación y sobre el bienestar económico, como Breyer abogaba hace 35 años. En los 35 años que han pasado desde que esas palabras se escribieran una abundante investigación, de hecho una gigantesca cantidad de investigación, fue realizada en el campo de la cual muy poca ha tenido una visión critica. De hecho, hasta los eventos de finales de los ' 90 ayudaran a reabrir el debate, la mayoría de las investigaciones se sustentaron en el 
principio general que la propiedad intelectual es buena para la sociedad en su conjunto, y no mala como nosotros reivindicamos aquí y en trabajos afines (ver por ejemplo Boldrin y Levine [2005a, 2005b] y las referencias incluidas en ellos). Esto se debe a una razón fundamental: la sabiduría popular de economía y derecho argumentan que los mercados competitivos no son adecuados para el comercio de copias de ideas, ya que las ideas son intrínsecamente diferente son distintas de cualquier otro bien. Como la mayoría de estos argumentos son incorrectos, a sus falacias ahora nos volcamos.

En lugar de argumentar si la protección de la propiedad intelectual debe extenderse o no, si debería durar 20 años para patentes y 75 para copyright, o al revés, nos gustaría cuestionarnos la mismísima idea de que la propiedad intelectual es necesaria y útil para fomentar la invención. Nuestro afirmación principal es la siguiente: exceptuando algunos casos menores la propiedad intelectual no es necesaria para alcanzar una innovación eficiente. La asignación eficiente del beneficio de la innovación puede y sería alcanzado mediante mercados competitivos correctamente regulados, y la distribución del beneficio entre inventores, imitadores y consumidores proveería, en promedio, los incentivos correctos para que se generasen descubrimientos en la sociedad. Por lo tanto, como principio legislativo, la propiedad intelectual debería ser eliminada y reemplazada por un sistema opuesto al de los derechos de propiedad. Un sistema en donde los creadores tengan los mismo derechos que otros productores, esto es: el derecho de ser dueños y vender los derechos de sus trabajos, y donde el poder del monopolio legal no esté asignado a sus ideas, salvo que un caso substancial se haga para mostrar que la innovación no se materializaría sin el privilegio monopólico específico.

Para comprender la falacia popular uno necesita comenzar por examinar el principio básico, formulado tiempo atrás por Kenneth Arrow [1962], por el cual las ideas y la información constituyen un tipo de bien muy particular, no adecuado para ser comerciado en el mercado competitivo. Esto no es cierto: en la mayoría de las dimensiones, las ideas no son distintas que el resto de los bienes genéricos, y aquellas dimensiones que en la que son diferentes no afectan el funcionamiento de los mercados competitivos. Aquí están algunos de los argumentos habituales, que han mostrado ser falaces.

(I) Se argumenta que en los mercados competitivos los innovadores no podrían apropiarse más que de una infinitesima parte del valor social de sus ideas.

Esto es un tema recurrente en la literatura de negocios, management y organización industrial, donde aparentemente se cree que la eficiencia económica requiere que los innovadores (o nuestro supuesto, los productores en general) se apropien de todo el valor social de sus productos. Si este fuera el caso, cualquier transacción en donde se generara un beneficio social seria ineficiente ya que los productores estarían «olvidándose algo en la mesa» de los consumidores. 
Aunque como muestra nuestra última nota al pie esto era muy claro para Breyer en 1970, una gran parte de la literatura escrita por auto proclamados expertos en economía y administración, continúa afirmando lo contrario. Pero, obviamente, la provisión socialmente eficiente de ideas/bienes requiere que todas las ideas/bienes con un beneficio social (esto es, que el valor social sea mayor o igual al costo social) sean producidos. ¿Cuánto de ese beneficio se divida entre productores, consumidores y otras entidades (los proveedores de bienes intermedios, gobierno, etc.) podría tener consecuencias, y generalmente tendrá, si todos los bienes con beneficio social son producidos, pero no hay presunción alguna de que muy pocos bienes serán creados salvo que los productores se apropien de todo el beneficio social. De hecho, generalmente esperaríamos que los productores lleven los bienes o ideas al mercado, siempre y cuando el costo privado de hacerlo no exceda las ganancias privadas de hacerlo.

Por lo tanto, desde una perspectiva social, uno podría preguntarse si para todas las ideas con un beneficio social, es cierto que el sistema de precios competitivo permite a los productores apropiarse de suficiente ingresos como para compensar el costo de oportunidad privado. Aunque parezca extraño, esta pregunta rara vez se hace en la literatura teórica sobre innovaciones, y, al menos hasta donde nos permite nuestro conocimiento, nunca en la literatura empírica. Como hemos demostrado en Boldrin y Levine [1999, 2004a], esta falacia olvida el hecho que las ideas combinan atributos tanto de bienes de consumo como de bienes de capital. Se pueden utilizar directamente para consumo, como por ejemplo leer un libro o mirar una película, o pueden utilizarse como insumo en la producción, haciendo copias de un libro o película, o para producir otros bienes, como por ejemplo utilizar la idea para mejorar el proceso de producción.

El hecho que la copia original de la idea sea el bien capital (el árbol) desde donde las otras copias (los frutos) deben ser creadas, permite al productor apropiarse del valor actual neto de todas las copias futuras a través del sistema de precios competitivo. Las semillas de maíz, por ejemplo, se pueden comer o ser utilizadas para producir maíz adicional, y por lo tanto combinan las características de bien de consumo y de capital. Los mercados competitivos de maíz generan los incentivos apropiados para invertir en semillas de maíz. La copia inicial de una idea (o copias cuando el proceso de innovación es simultaneo) es generalmente producidas a través de un proceso distinto que el utilizado para producir las copias subsiguientes, como en el caso de la investigación y la enseñanza. La mayoría de los bienes de capital (investigación originaria) son utilizados para producir bienes distintos que ellos mismos - pero el hecho que los bienes de capital pueden ser utilizados para reproducirse a sí mismos no impone ningún problema para los mercados competitivos. En la industria de los semiconductores, por ejemplo, la reducción del tamaño de los chips hace posible construir equipamiento que puede ser utilizado para producir chips incluso mas pequeños. 
(II) Hay insinuaciones que las ideas están sujetas a «externalidades de derrame» o lo que podríamos denominar filtrado de información. Esto es, la existencia de la idea permite a la gente conocer y hacer uso de la idea sin el permiso de sus autores.

Algunos incluso argumentan que las ideas se pueden copiar en forma gratuita. En la práctica, muy pocas ideas están sujetas al filtrado de información y en todos los casos es caro reproducirlas. En el caso de las creaciones con potencial copyright, en donde las ideas se traducen en objetos físicos como libros, la filtración de información no es un problema. En el caso de los avances científicos, la reflección muestra que tampoco es el caso. Mientras que las ideas científicas están en algún sentido disponibles para todo el mundo, las copias utilizables de las ideas científicas no son muy fáciles de hallar. Incluso las leyes de Newton, nuestro ejemplo de la próxima sección, requieren una cantidad de esfuerzo y tiempo sustancial para poder entenderlas.

Para propósitos prácticos, las copias están limitadas a la gente que entiende que las leyes y libros que los explican. Sin pagarle a alguien que te explique las leyes de Newton, no es muy probable que puedas aprenderlas simplemente porque son de dominio público. Y como los maestros y profesores nos ganamos la vida mediante nuestra habilidad de comunicar ideas a los otros, creamos copias nuevas en el proceso. Hay una enorme evidencia histórica que muestra que la difusión y adopción de innovaciones cuesta dinero y tiempo.

(III) Dejar que las ideas sean de dominio público, como sería el caso de un sistema en donde la propiedad intelectual sea ilegal, sería socialmente ineficiente y condenaría la actividad creativa a la «tragedia de los comunes».

Ya hemos discutido en la sección 2.2 porque esto es totalmente incorrecto. Una vez que la patente o el copyright expiran hay muchas copias de la idea, cada una un buen sustituto de la otra y cada una adueñada por alguien. Si una persona quiere hacer uso de la idea, hacer copias o convertirla en otra cosa, primero debe adquirir una copia de sus dueños. Si hay muchos dueños, cada uno compitiendo por venderla, es posible que la pueda obtener relativamente barata, incluso si piensa transformarla en un bien nuevo valioso. Pero el hecho que puedas comprar ingredientes baratos es una consecuencia positiva de los mercados competitivos y no una consecuencia negativa. De hecho, la evidencia sugiere que el mercado para bienes de dominio publico funciona bien, con copias disponibles a un precio razonable: hallar la copia de un libro de Dickens, por ejemplo, no presenta inconvenientes. 


\section{Pensando sin las cadenas de la UIP}

En escritos previos hemos trabajado modelos matemáticos y cuantitativos -ver Boldrin y Levine (1999, 2002, 2004a)- para mostrar por qué la actividad creativa puede florecer en condiciones competitivas y no requeriría en teoría -y la práctica lo confirma- los privilegios monopólicos que la actual legislación de propiedad intelectual les concede a los creadores e inventores. Aquí ilustramos verbalmente la intuición básica de nuestro análisis, utilizando un ejemplo histórico conocido para fijar ideas.

El desarrollo económico en el largo plazo, y más generalmente el social, es el resultado de continuas creaciones de nuevos bienes, de su intercambio voluntario entre individuos y de la competición entre productores de distintos bienes, sean creadores o imitadores. Los economistas se han dado cuenta que sin innovaciones sostenidas la mejora en los niveles de vida sería lenta e inconsecuente. Este punto fue argumentado por la fuerza por Joseph Shumpeter en La teoría del Desarrollo Económico (1911). Con tecnología constante y un conjunto de bienes constantes, el proceso de acumulación del capital, basado únicamente en el ahorrote los ingresos durante la juventud, sólo generarían una fracción del incremento del ingreso per capita del que hemos sido testigos desde el inicio de la historia humana. La historia y el sentido común se conjuran en sugerir que la acumulación de capital bajo una tecnología constante no puede ir muy lejos debido a la presencia de recursos fijos y los retornos decrecientes que traen consigo. La innovación es el motor de cambio y del desarrollo económico, y por lo tanto, entender su naturaleza, los mecanismos internos y los factores sociales e institucionales que la generan o impiden, es uno de los problemas mas importantes que enfrentan las ciencias sociales. Es nuestra creencia que entender la innovación equivale a comprender la competencia, que lo ultimo es una condición necesaria de lo primero y que, en circunstancias generales, también es suficiente. Si la innovación es el flujo que nos enriquece, la competencia es el capullo de donde florece.

La innovación para nosotros es la creación de la primera copia de un bien/proceso/idea que no existía antes. Como la palabra «idea» se utiliza aquí para denotar todas las innovaciones, su uso debería ser brevemente clarificado. En nuestra terminología, la innovación de Isaac Newton no consistió sólo en pensar las leyes gravitacionales, sino en el proceso de concebirlas en su mente en primer lugar, y en formulas y en exposición escrita luego. Cuando, en 1687 completo el manuscrito de su Philosophiae naturalis principia matemática y la hizo publicar, «la innovación de Newton» estaba completada. Todas las copias subsecuentes de Principia eran una reproducción de la primera copia de su idea, y fueron producidas con una tecnología diferente de la que se utilizó para obtener el primer manuscrito. Notar que con copia nos referimos tanto a la copia física del libro o a la copia (igualmente física, aunque menos visible) de las leyes gravitacionales retenidas en el cerebro de otro científico u hombre común, esto es, capital humano valorado socialmente. De hecho, y esto es crucial, el valor social de la innovación de Newton se puede medir 
mejor con el numero de copias existentes en el segundo formato (capital humano propiamente dicho) que en el primer formato (copias del libro). Todas esas copias surgieron a partir de la copia original de Newton y el valor social de esta última sería mucho menor, incluso negligible, sin aquellas. La recompensa de Newton, tanto en términos de prestigio intelectual como en términos de riqueza y status social, se hizo tan grande debido a que muchas copias (de los dos tipos) del Principia fueron eventualmente reproducidas. En nuestra terminología, la primera copia de las leyes gravitacionales es el «prototipo» y contiene, por primera vez, la idea de Newton; la tecnología de innovación es la que Newton adopto para descubrir las leyes gravitacionales y escribir Principia. La tecnología de imitación es la utilizada por los subsecuentes editores del libro y por cualquier entendido y entrenado en el contenido de Principia. Notar algo muy relevante: el Principia fue publicado antes que el Estatuto de Anne introdujera algunos grados (débiles para los estándares actuales) de propiedad intelectual en el Reino Unido.

Notar que los productos finales de las dos tecnologías son, en términos de funcionalidad, equivalentes: una copia del Principia es una copia del Principia, y un humano que entiende los principios y las leyes de gravitación es, al menos desde este punto de vista estrecho, equivalente a cualquier humano que entiende los mismos principios y leyes. Este punto será relevante mas adelante, cuando discutamos el dominio público de ideas. Notar también que las dos tecnologías usan una variedad de insumos para obtener el producto final, que alguno de estos insumos son innovaciones previas (por ejemplo las Leyes de Kepler) y que estos insumos son adquiridos en mercados competitivos que no operan bajo la Ley de Propiedad Intelectual, pero que deben ser obtenidas de monopolistas adquiriendo licencias bajo la Ley de Propiedad Intelectual. Hay dos excepciones a lo que acabamos de decir. Primero si la tecnología de innovación utiliza un recurso particularmente escaso, la genialidad de Newton en este caso, que limita el número de prototipos iniciales que pueden obtenerse. Si nos hubiera buscado una invención menos dramática, la creación en simultaneo por un número de creadores diferentes e independientes hubiera sido mas probable, como es el caso normalmente en la practica. Igualmente, la cantidad total de habilidad creativa disponible en cualquier momento para realizar prototipos de nuevas ideas es limitado. En la jerga económica, en cualquier momento siempre existe una cantidad limitada de capacidad creativa para realizar prototipos. En el particular caso de las invenciones científicas de las creaciones artísticas, esta limitación de capacidad creativa puede persistir por un largo tiempo: los nuevos descubrimientos científicos pueden ser muy difíciles de comprender, y por ello tenemos programas de doctorado y post doctorados y performances en vivo de música difícil de imitar, razón por la que se agotan las entradas para los conciertos en vivo y además son habitualmente caros. La tecnología de imitación también utiliza un tipo particular de insumo, y eso es la copia pre-existente del Principia (en caso que estemos considerando publicar copias del libro) o, más generalmente, alguien que haya entendido su contenido (en caso que estemos considerando a un estudiante para aprender las leyes gravitacionales). De cualquier forma, también este insumo parti- 
cular tiene una oferta limitada; técnicamente hablando esto es cierto en cualquier momento, incluso ahora, pero es especialmente cierto en periodos cercanos en el tiempo al momento en que el primer prototipo del Principia apareció. En resumen, la tecnología de imitación también enfrenta capacidad productiva limitada, cuya capacidad esta determinada principalmente por el numero de copias de la idea «las leyes gravitacionales de Newton» incorporados a los libros/humanos en un punto del tiempo.

Una pequeña reflección muestra que este conjunto de propiedades no es especifico del caso particular del Principia, pero que aplica a un conjunto amplio (incluso universal) de otras innovaciones. Las diferencias son cuantitativas y nunca cualitativas: las nuevas ideas valiosas están siempre incorporadas en la gente o en las personas; la capacidad de innovación siempre es limitada; la imitación/reproducción siempre requiere copias de las ideas y por lo tanto surge del prototipo original incluso en los casos aislados en que la imitación no requiera grandes inversiones; la capacidad reproductiva también es limitada por un número sustancial de períodos luego de que la innovación tiene lugar; las nuevas ideas casi siempre requieren viejas ideas para ser creadas, y la creación es cada vez más un proceso complejo y acumulativo; finalmente, los consumidores siempre están impacientes y prefieren el producto hoy en lugar de mañana. Nuestro análisis teórico se basa en estas propiedades, y otra más: le llevo bastante tiempo a Newton llegar a las leyes gravitacionales (no obstante las manzanas) y por lo que sabemos, más aun para articularlos en un manuscrito del Principia. Aun por encima, el Principia no fue una pequeña o infinitesimal desviación del conocimiento previo o una mejora de este sino una substancial. ¡ $\mathrm{Al}$ menos cualitativamente, esta propiedad también es general! Producir el prototipo, vía la invención de tecnología, a menudo requiere una gran inversión, que podemos pensarla como indivisible. Si bien no es cierto que una cuantiosa indivisibilidad esta involucrada en la producción de prototipos de cada idea, es cierto que este es a menudo el caso, y que esta característica de la actividad creativa debería ser tenida debidamente en cuenta cuando se discuta la asignación del beneficio social de la actividad creativa.

Finalmente, unas breves palabras para clarificar nuestra forma de pensar el problema. Nos preguntamos qué es socialmente optimo, y cómo deberían ser provistos (por ejemplo qué estructura de mercado puede proveer los incentivos correctos) para que la cantidad socialmente optima de actividad creativa tenga lugar. El problema de proveer incentivos para innovar no debería confundirse con la protección de rentas a intermediarios, o rentas a artistas establecidos, o a creadores en general. La cuestión aquí no es cómo hacer a los creadores ricos o lo mas ricos posible, sino como asignarles lo suficiente del beneficio de la actividad creativa de forma que no tengan incentivo a hacerla en forma eficiente, desde un punto de vista social. Esto requiere concentrarse en el concepto de costo de oportunidad, esto es, preguntarse: cuando un potencial innovador considera la decisión entre realizar una actividad creativa o hacer otra actividad, su costo de oportunidad esta determinado por cuanto ingreso recibiría por hacer esa otra actividad. La eficiencia requiere que, en caso de 
que el innovador se decida por la innovación, reciba de esta última al menos lo que hubiera recibido de la actividad alternativa, esto es: su costo de oportunidad. Cuando la estructura del mercado permite al innovador recibir más que su costo de oportunidad, esta renta adicional no tiene ninguna utilidad social. Per se, esta renta adicional podría ser una simple transferencia que no afecta la eficiencia económica; sin embargo, más frecuentemente que no, y en particular cuando está involucrado algún poder monopólico, esta renta adicional se le debe al innovador porque tiene incentivos a proveer menos innovaciones, o menos copias de sus innovaciones, que lo socialmente eficiente. En este caso, la renta adicional no es únicamente una transferencia neutral de los consumidores a los innovadores (lo que podría ser injusto, pero irrelevante para la eficiencia) sino un impuesto socialmente costoso y ineficiente a los consumidores, menos copias disponibles para la gente que lo deseable y factible tecnológicamente. Nuestra crítica a las actuales leyes de propiedad intelectual se focalizan en este segundo aspecto.

La innovación tecnológica cambia continuamente el costo de oportunidad y los valores de reserva de los agentes involucrados en la creación. Por ejemplo, la invención de la imprenta hizo innecesaria para la producción de nuevos libros la artesanía acumulada durante siglos por artesanos y monjes. Esto fue una bendición para los escritores y lectores, pero una maldición para aquellos artesanos que de repente se encontraron sin su derecho a un porcentaje del valor social de cada libro, nuevo o viejo. Dada las actuales tecnologías, y la continua mejora en la tecnología de innovación y reproducción, seria crucial medir cual es el costo de oportunidad para creadores e innovadores. Desafortunadamente, esta es una tarea a la que los economistas empíricos le han dedicado una mínima atención, en particular los del área de organización industrial, y no tenemos conocimiento de ningún estudio que intente estimar el ingreso futuro esperado necesario para atraer a potenciales innovadores a la actividad creativa.

\section{Conclusiones}

Mientras que el funcionamiento de la competencia en el mercado de bienes ha sido objeto de estudio por un tiempo prolongado, y nuestro conocimiento parece haber progresado substancialmente desde los tiempos de Adam Smith, frecuentemente no es el caso con el mercado de ideas. De hecho, existe una visión generalizada de que las ideas son dramáticamente e intrínsecamente diferentes de los bienes y que la «economía del conocimiento» debe ser basada en premisas distintas que las que se adoptan en el resto de la economía. En nuestro trabajo reconsideramos este punto y concluimos que, mientras que la teoría económica de las ideas requiere modificaciones en algunos de los supuestos comunes con los que se manejan los mercados para bienes regulares, esas diferencias son mucho menos dramáticas que las que uno hubiera esperado a prima facie, y que una gran parte del conocimiento económico aplica igual de bien a la economía del conocimiento. Esto nos permite 
reconsiderar en forma crítica un conjunto de argumentos teóricos que se encuentran en la intersección entre la teoría de la innovación y el cambio tecnológico y el crecimiento y la teoría de comercio, para concluir que la mayor parte del saber popular, incluyendo la sabiduría legal citada por la Corte Suprema de los Estados Unidos, no tiene fundamento empírico o no es consistente desde el punto de vista lógico, y que algunos saberes viejos y posiblemente desconocidos, deberían ser recuperados para el estudio del cambio tecnológico, crecimiento y comercio.

Descubrir cómo las ideas son diferentes al resto de los bienes es central para entender el mercado de las ideas y los incentivos para la adopción de nuevas ideas. El punto de partida del análisis económico de la innovación es reconocer que la unidad relevante desde el punto de vista económico es la copia de una idea. Esto es, típicamente muchas copias de una idea existen tanto en forma física, como un libro, un archivo de computadora o una pieza de una maquinaria, o en la forma del conocimiento incorporadas por la gente que conoce y entiende la idea. Las copias de las ideas son etiquetadas con una variedad de nombres cuando son aprendidas por los humanos, lo que a veces obscurece su naturaleza común: técnica, conocimiento, capital humano normas, y así sucesivamente. Una inspección meticulosa muestra sin embargo, que cada todos y cada uno de esas entidades aparentemente distintas es al final de cuentas nada más que una copia de una idea, y que la ultima fue descubierta primero por la persona que actualmente la tiene incorporada o adquirida con un coste (posiblemente vía observación e imitación) por otras personas, en quienes había estado previamente incorporada. Las copias económicamente valiosas de las ideas no caen del cielo como maná, sino que son el producto de esfuerzos intencionados y costosos. Sólo estas copias importan, primero porque si fueran borradas la idea dejaría de tener valor y segundo, en el sentido de que las copias son un buen sustituto entre sí: ya sea que la copia de una idea es la copia original o la centésima copia, tiene la misma utilidad económica. Desde la perspectiva de los mercados, por lo tanto, los derechos de propiedad en las copias de las ideas están aseguradas por las leyes ordinarias contra el robo -lo que habitualmente se conoce como «propiedad intelectual» no protege la propiedad de las copias de las ideas, sino que es un monopolio sobre la gente que hace uso de la copia de la idea.

Debemos mencionar que el argumento de Lemley de no hay ninguna razón para que de existir derechos de monopolio se le otorguen al autor, es incorrecto. Más allá de quién comience con los derechos de monopolio, en tanto y en cuanto puedan ser vendidos sin costos de transacción prohibitivos, terminarán en manos de aquel que pueda manejarlos en forma mas eficiente. En la práctica la mayoría de los copyright son transferidos a corporaciones y publicistas. Si los derechos de monopolio deben ser provistos, la ventaja de proveerlos al creador (más allá de la dificultad obvia de averiguar a quien otorgárselos) es que crea un incentivo adicional para crear, por minúsculo que sea. 


\section{Referencias}

[1] ARROW, K. [1962]. «Economic Welfare and the Allocation of Resources for Invention», in The Rate and Direction of Inventive Activity: Economic and Social Factors, A Report of the National Bureau of Economic Research, 609-25. Princeton University Press,

[2] BOLDRIN, M. y D. K. LEVINE [1999]. «Perfectly Competitive Innovation», available at www.dlevine.com y www.econ.umn.edu/ mboldrin

[3] BOLDRIN, M. y D. K. LEVINE [2002]. «The Case Against Intellectual Property», American Economic Review Papers and Proceedings, 92, 209-212.

[4] BOLDRIN, M. y D. K. LEVINE [2004a]. «IER Lawrence Klein Lecture: The Case Against Intellectual Monopoly», International Economic Review, 45, 327-350.

[5] BOLDRIN, M. y D. K. LEVINE [2004b]. «IP and Market Size», available at www.dlevine.com and www.econ.umn.edu/ mboldrin

[6] BOLDRIN, M. y D.K. LEVINE [2005a]. «The Economics of Ideas and Intellectual Property», Proceedings of the National Academy of Sciences, 102, 1252-1256.

[7] BOLDRIN, M. y D. K. LEVINE [2005b]. Against Intellectual Monopoly, www.dklevine.com/general/intellectual/against.htm

[8] BREYER, S. [1970]. «The Uneasy Case for Copyright. A Study of Copyright in Books, Photocopies, and Computer Programs», Harvard Law Review 84, 281-351.

[9] BRITT, B. [1990]. «International Marketing: Disney's Global Goals», Marketing.

[10] KARJALA, D. S. [1998]. «Statement of Copyright and Intellectual Law Professors in Opposition to H.R. 604, H.R. 2589 and S. 505, The Copyright Term Extension Act, Submitted to the Joint Committees of the Judiciary.»

[11] KARJALA, D. S. [2004]. «Opposing Copyright Extension», www.public.asu.edu/ dkarjala/legmats/hatch95.html

[12] LANDES, W. M. y R. A. POSNER [1989]. «An Economic Analyisis of Copyright Law», The Journal of Legal Studies 325-363.

[13] LANDES, W. M. y R. A. Posner [2003]. The Economic Structure of Intellectual Property Law, Harvard University Press.

[14] LEMLEY, M. A. [2004]. «Ex Ante versus Ex Post Justifications for Intellectual Property», mimeo, UC Berkeley

[15] LINDSEY, B. [2001]. Against the Dead Hand: The Uncertain Struggle for Global Capitalism, Wiley

[16] POSNER, R.A. [2004]. «Eldred and Fair Use», The Economists' Voice, September, http://www.bepress.com/ev/vol1/iss1/art3.

[17] SEABRIGHT, P. [2004]. The Company of Strangers: A Natural History of Economic Life. Princeton University Press. 
